\title{
Effect of Oak Chip Addition at Different Winemaking Stages on Phenolic Composition of Moravia Agria Red Wines
}

\author{
M.A. Gómez Gallego ${ }^{1}$, E. Sánchez-Palomo ${ }^{1, *}$, I. Hermosín-Gutiérrez ${ }^{2}$, M.A. González Viñas ${ }^{1}$
}

(1) Departamento de Química Analítica y Tecnología de los Alimentos, Facultad de Ciencias Químicas, Universidad de CastillaLa Mancha, Av. Camilo José Cela 10, 13071, Ciudad Real, Spain

(2) Instituto Regional de Investigación Científica Aplicada, Escuela de Ingenieros Agrónomos, Universidad de Castilla-La Mancha, Ronda de Calatrava 7, 13071 Ciudad Real, Spain

Submitted for publication: May 2014

Accepted for publication: September 2014

Key words: Moravia Agria, oak chips, phenolic compounds, antioxidant capacity, colour

\begin{abstract}
This study compared changes in the phenolic composition of Moravia Agria wine and its effect on colour, co-pigmentation as well as on physicochemical properties, such as antioxidant capacity, caused by adding oak chips at different stages of the winemaking process. Moravia Agria control wine was made following traditional winemaking processes, without oak chips. Oak chips were added to the rest of the wines at two dose rates $(3$ and $6 \mathrm{~g} / \mathrm{L}$ ) at different stages of the winemaking process: for one week during alcoholic fermentation, during malolactic fermentation and in young red Moravia Agria wine. Only slight significant differences were found in phenolic composition, antioxidant activity and chromatic characteristics between the Moravia Agria wines treated with oak chips and the control wine. However, oak chip addition slightly decreased the content of non-polymeric red pigments (monomeric anthocyanins and pyranoanthocyanins) and also of resveratrol-monomer stilbenes. It is suggested that oak chip addition to Moravia Agria wines can be selected as part of the targeted sensory profile (relative intensity of sensory descriptors provided by grape and oak wood), since only a few changes have been observed in the phenolic profiles, antioxidant capacity value and colour characteristics.
\end{abstract}

\section{INTRODUCTION}

Wine ageing is a well-known winemaking practice for improving wine quality and organoleptic characteristics. This practice modifies wine composition due to the compounds extracted from the wood and the chemical reactions that take place when oxygen passes through the wood pores. Wines aged in wood barrels are highly appreciated by consumers. Market research has pointed out that $88 \%$ of people prefer red wines aged in wood to young red wines (Pérez-Magariño et al., 2007). Nevertheless, ageing wines in wood is expensive, and barrels take up a lot of space in the winery and their lifetime is not very long. For these reasons, new, inexpensive techniques have been developed to simplify the ageing process while ensuring that the woodrelated volatiles are released into the wine to provide sensory properties similar to wines aged in barrels. These alternatives include oak chips, shavings and larger pieces of oak. These alternatives to oak ageing have been an extended practice in USA, Australia and other countries, such as Chile, for several years, but they were not legal practice in EU countries until October 2006, when the EU approved the use of wood chips in winemaking and the designation and presentation of wine so treated (Commission Regulation, EC, 2006). The relevant regulation states that "the pieces of oak wood" must come exclusively from the Quercus genus.

Some scientific papers have confirmed that wines treated with oak chips or staves mature more quickly than wines aged in wood barrels, and that more colour and more extraction of some volatile compounds is obtained (Arapitsas et al., 2004; Del Álamo-Sanza et al., 2004, Moyano et al., 2009). Over the last few years, some papers have focused on the phenolic composition and its influence on the colour of red wines macerated with chips (McCord, 2003; Del Álamo-Sanza et al., 2004; Del Álamo-Sanza \& Nevares-Dominguez, 2006; Gómez-Cordovés et al., 2006; Gortzi et al., 2013; GonzálezSáiz et al., 2014).

The Moravia Agria variety was selected for this research. It is a traditional variety at threat of extinction in the La Mancha region. The phenolic composition, volatile composition, aroma sensory profile and impact aroma compounds of the young red wines made from this grape variety have been studied in previous works (GarcíaCarpintero et al., 2012; Gómez Gallego et al., 2012a). The aim of this study was to evaluate the similarities or differences in the phenolic composition and their effects on colour, co-pigmentation as well as on physicochemical properties, using the antioxidant capacity of Moravia Agria variety wines that had been in contact with oak chips at 
different stages of the winemaking process: during alcoholic fermentation, during malolactic fermentation and after malolactic fermentation (using two quantities of oak chips at each stage -3 and $6 \mathrm{~g} / \mathrm{L}$ ). This analysis allows us to select the best treatment as an alternative to oak barrels in an effort to simplify the ageing process and reduce operating costs.

\section{MATERIALS AND METHODS}

\section{Wine Samples}

Red grapes of cv. Moravia Agria were obtained from a vineyard in the La Mancha region in mid-southeast Spain. The grapes were harvested at their optimal ripening stage and had good sanitary conditions. Seven batches of grapes ( 8 $\mathrm{kg}$ each) were treated in vats of $10 \mathrm{~L}$ with skin maceration until the end of alcoholic fermentation. Moravia Agria control wine $(\mathrm{CW})$ made without the addition of oak chips was processed following the traditional red winemaking process. The rest of the Moravia Agria wines were vinified with the addition of oak chips, at two dose rates $(3 \mathrm{~g} / \mathrm{L}$ and 6 $\mathrm{g} / \mathrm{L})$, during different stages of the winemaking process. The amount of chips used in this study was selected so as to avoid an excessive impact of the wood character on wines that could produce a negative effect in the taster (Pérez-Coello et al., 2000; Guchu et al., 2006).

AFA3 and AFA6 wines were elaborated with the addition of $3 \mathrm{~g} / \mathrm{L}$ and $6 \mathrm{~g} / \mathrm{L}$ oak chips respectively, before the beginning of the alcoholic fermentation (AF). The wood was added to MFA3 and MFA6 wines before the beginning of the malolactic fermentation (MLF) at the same concentrations as the previous samples. Finally, oak chips were added to the finished Moravia Agria wine for samples PFA3 and PFA6 and they were kept in contact with the wine for one week. Each wine elaboration was carried out in duplicate. The oak chips were obtained from a mix of American and French oak with medium toast (Nobile Original Blend, Lafford).

Winemaking conditions involved the addition of $100 \mathrm{ppm}$ of $\mathrm{SO}_{2}$ as $\mathrm{K}_{2} \mathrm{~S}_{2} \mathrm{O}_{7}$, after stemming and crushing, and inoculation with Saccharomyces cerevisiae selected yeasts (UCLM S325, Fould-Springer) at a fermentation temperature $24^{\circ} \mathrm{C}$. Manual punching down was done twice a day. Separation of the wines from the solids was performed when relative density reached a constant value. The malolactic fermentation then was induced by inoculation with Oenococcus oeni (Lactobacter SP1; Laffort). This second fermentation finished in two to three weeks, as confirmed by TLC (thin layer chromatography), and then the wines were racked, filtered through $1.2 \mu \mathrm{m}$ membranes (Millipore, Bedford, MA, USA), bottled, and stored in an air-conditioned room kept at 16 to $18^{\circ} \mathrm{C}$ until the sensory evaluations were performed. All fermentations were carried out in duplicate.

\section{Standard chemical analysis of wines}

The total and volatile acidity, total and free $\mathrm{SO}_{2}, \mathrm{pH}$ and ethanol $(\%, v / v)$ of these wines at the moment of bottling were analysed according to the methods proposed by the O.I.V. in 2006.

\section{Spectrophotometric measurement of total polyphenols}

Total polyphenols were analysed according to the method proposed by Mazza et al. (1999). Calibration curves were obtained from solutions of different concentrations of gallic acid. Determinations were performed in duplicate.

\section{Wine sample preparation for analysis of non-anthocyanin phenolic compounds}

Wine sample preparation was done according to the method proposed by Castillo-Muñoz et al. (2007) using solid-phase extraction Oasis ${ }^{\circledR}$ MCX cartridges (Waters $-6 \mathrm{~cm}^{3}$ capacity filled with $500 \mathrm{mg}$ of absorbent).

\section{DETERMINATION OF PHENOLIC COMPOSITION BY HPLC-DAD \\ Chemicals}

All solvents were of HPLC quality and all chemicals of analytical grade (>99\%). Water was of Milli-Q quality. The commercial standards used were from Phytolab (Vestenbergsgreuth, Germany): malvidin 3-glucoside, caftaric, caffeic and p-coumaric acids, trans-piceid and (-)-epigallocatechin. The following commercial standards from Extrasynthese (Genay, France) were used: kaempferol, quercetin, isorhamnetin, myricetin and syringetin, and the 3- glucosides of kaempferol, quercetin, isorhamnetin and syringetin. The commercial standards from Sigma (Tres Cantos, Madrid, Spain) were trans-resveratrol, $(+)$ - catechin and (-)-epicatechin. Other non-commercial standards (myricetin 3-glucoside, quercetin 3-glucuronide, vitisin A, 10-didydroxyphenyl-pyranomalvidin-3-glucoside) were kindly supplied by Dr Ulrich Engelhardt and Dr Peter Winterhalter (Institute of Food Chemistry, Technical University of Braunschweig, Germany). The trans isomers of resveratrol and piceid (resveratrol 3-glucoside) were transformed into their respective cis isomers by UV irradiation (366 nm light during five minutes in quartz vials) of $25 \% \mathrm{MeOH}$ solutions of the trans isomers. All the standards were used for identification and quantification by means of calibration curves, covering the expected concentration ranges (usually 0 to $100 \mathrm{mg} / \mathrm{L}$, with the exception of malvidin 3-glucoside, which covered a range of 0 to $1000 \mathrm{mg} / \mathrm{L}$ ). When a standard was not available, the quantification was done using the calibration curve of the most similar compound (with subsequent molecular mass correction): malvidin 3-glucoside was used for all native grape anthocyanins; flavonol 3-glycosides with non-available standard as their corresponding 3-glucoside derivatives; all vitisin-like and hydroxyphenyl-like pyranoanthocyanins as vitisin $\mathrm{A}$ and 10-didydroxyphenyl-pyranomalvidin-3glucoside respectively; coutaric acid and ethyl p-coumarate as p-coumaric acid; and ethyl caffeate as caffeic acid. The sum total of flavonols was calculated after the conversion of every individual concentration in $\mathrm{mg} / \mathrm{L}$ into micromole/ $\mathrm{L}$, using their corresponding molecular weights.

\section{HPLC-DAD method}

HPLC separation, identification and quantification of wine phenolic compounds were performed on an Agilent 1100 Series system (Agilent, Germany) equipped with a DAD detector (G1315B) and coupled to an Agilent Chem Station (version B.01.03) data-processing station.

Wine samples were directly injected for the analysis 
of anthocyanins and pyranoanthocyanins, whereas anthocyanin-free wine phenolic extract was used for analysing non-anthocyanin phenolic compounds. The samples were injected $(50 \mu \mathrm{L})$ after filtration $(0.20 \mu \mathrm{m}$, polyester membrane, Chromafil PET 20/25, MachereyNagel, Düren, Germany) on a reversed-phase column Zorbax Eclipse XDB-C18 $(4.6 \times 250 \mathrm{~mm} ; 5 \mu \mathrm{m}$ particle; Agilent, Waldbronn, Germany), and thermostated at $40^{\circ} \mathrm{C}$.

The chromatographic conditions, solvents system and elution gradient used for the analysis of anthocyanins and pyranoanthocyanins were those described previously (Rentzsch et al., 2010). The solvents were water/acetonitrile/ formic acid (87:3:10, v/v/v, solvent A; 40:50:10, v/v/v, solvent B), and the flow rate was $0.63 \mathrm{~mL} / \mathrm{min}$. The linear gradient for solvent $\mathrm{B}$ was: $0 \mathrm{~min}, 6 \% ; 15 \mathrm{~min}, 30 \%$; 30 min, 50\%; $35 \mathrm{~min}, 60 \%$; $38 \mathrm{~min}, 60 \%$; and $46 \mathrm{~min}, 6 \%$. For quantification, DAD chromatograms were extracted at $520 \mathrm{~nm}$ for native grape anthocyanins and at $510 \mathrm{~nm}$ for pyranoanthocyanins.

The non-anthocyanin phenolic compounds (flavonols, hydroxycinnamic acids, flavan-3-ol monomers, and resveratrol-type stilbenes) were analysed by injection of the anthocyanin-free wine phenolic extracts, using the same chromatographic equipment and conditions previously described (Castillo-Muñoz et al., 2009). Quantification was done by extracting DAD chromatograms at $360 \mathrm{~nm}$ (flavonols), $320 \mathrm{~nm}$ (hydroxycinnamic acid derivatives and resveratrol-type stilbenes), and $280 \mathrm{~nm}$ (flavan-3-ol monomers).

All the aforementioned phenolic compounds were identified on the basis of their UV spectra and using standards that matched those previously identified by LCMS using the same HPLC equipment and under the same chromatographic conditions (Castillo-Muñoz et al., 2009; Nixdorf \& Hermosín-Gutiérrez, 2010).

\section{Co-pigmented anthocyanins}

The contribution of co-pigmented anthocyanins to the total wine colour at $\mathrm{pH} 3.6$ (\% co-pigmentation) was determined following Boulton's method as described by HermosínGutiérrez (2003). While the selected pH value may not be the $\mathrm{pH}$ conditions for each particular wine, it provides the only rational basis on which to compare colour components, which are dependent on $\mathrm{pH}$ effects, across all wines.

Chromatic characteristics in the CIELCh space of wines The parameters of the CIELCh colour space ( $\mathrm{L}^{*}, \mathrm{C}^{*}$ and $\mathrm{h}^{*}$ ) were calculated according to a proposed simplified method for red wines (Pérez-Caballero et al., 2003) after filtration of the samples through $0.45 \mu \mathrm{m}$ nylon membranes (Millipore). To avoid $\mathrm{pH}$ effects, all the measurements were made after $\mathrm{pH}$ adjustment to the same reference value (3.6) used for the estimation of co-pigmented anthocyanins.

\section{Determination of antioxidant capacity by radical DPPH}

The above procedure consisted of adding $100 \mu \mathrm{L}$ of wine, diluted in methanol, to $2.9 \mathrm{~mL}$ of a DPPH (2,2-diphenyl-1picrylhydracyl, Fluka Chemie) radical methanolic solution $\left(6 \times 10^{-5} \mathrm{~mol} / \mathrm{L}\right)$, and measuring the percentage of absorbance decrease at $515 \mathrm{~nm}$ after $25 \mathrm{~min}$. The measurement had to be in the range of 20 to $80 \%$ of the initial DPPH absorbance (wine dilution with methanol is adjusted to achieve this goal; for red wines, usual dilution factors are within $1 / 10$ and $1 / 20$ ). The quantification of the antioxidant capacity was done by calibration curves obtained from methanolic solutions of Trolox (6-hydroxy-2,5,7,8-tetramethylchroman2-carboxylic acid, Fluka Chemie), a commercial watersoluble vitamin $\mathrm{E}$ that is used to standardise the results from different studies dealing with food antioxidant capacity within a concentration range of between 0.19 and $0.93 \mathrm{~mol} / \mathrm{L}$ (Brand-Williams et al., 1995).

\section{Data analysis}

All statistical analyses were performed using the SPSS version 19.0 for Windows statistical package. The StudentNewman-Keuls test was applied to discriminate between the means of the chemical data.

\section{RESULTS AND DISCUSSION \\ Conventional analysis}

The conventional analytical data of the wines at the moment of bottling are shown in Table 1 and were consistent with a correct elaboration and within the usual values shown by red wines of the Spanish region of Castilla-La Mancha. Ethanol, $\mathrm{pH}$ and volatile acidity were as expected for red wines and no significant differences were found between the samples despite independent winemaking elaborations for each wine. On the other hand, total acidity was slightly higher than other red wines from this region, but this is a varietal characteristic of Moravia Agria grapes (Gómez Gallego et al., 2012b). The concentrations of free and total $\mathrm{SO}_{2}$ were within the ranges allowed by legislation.

\section{Total polyphenols}

Table 1 shows the total amounts of polyphenolic compounds. All wines presented contents of total polyphenols within the usual ranges found for young red wines (Ribéreau-Gayon et al., 2000). No significant differences were found between the control wine $(\mathrm{CW})$ and the wines treated with oak chips. The content of total polyphenols shown by all the studied wines was in agreement with the levels of phenolic compounds previously reported for the Moravia Agria grape variety (Gómez Gallego et al., 2012b).

\section{Antioxidant capacity}

The antioxidant activity of the studied wines (Table 1) ranged within 9.89 to $12.10 \mathrm{mmol} / \mathrm{L}$ (as Trolox equivalents), with no significant differences between samples, in agreement with the reported range (1.2 to $25.5 \mathrm{mmol} / \mathrm{L})$ for red wines (Landrault et al., 2001; Fernández-Pachón et al., 2004). It could be suggested that the application of oak chips did not produce a relevant effect on antioxidant capacity, very likely because the application of this technique in Moravia Agria wines provoked an almost balanced decrease and increase in the concentrations of some phenolic compounds with demonstrated antioxidant properties (anthocyanins, flavan3-ols, and stilbenes, vs. flavonols, respectively). 
TABLE 1

Conventional analytical data of the red wines at the moment of bottling, total polyphenols and antioxidant capacity (TAAE) (mean value and $\mathrm{SD} ; \mathrm{n}=2$ ).

\begin{tabular}{|c|c|c|c|c|c|c|c|c|}
\hline & $\begin{array}{l}\text { Ethanol } \\
(\% \mathrm{~V} / \mathrm{V})\end{array}$ & pH & $\begin{array}{l}\text { Total acidity } \\
\text { (g/L as } \\
\text { Tartaric acid) }\end{array}$ & $\begin{array}{c}\text { Volatile acidity } \\
\text { (g/L as Tartaric } \\
\text { acid) }\end{array}$ & $\begin{array}{c}\text { SO, Free } \\
(\mathrm{ppm})\end{array}$ & $\begin{array}{c}\mathrm{SO}_{2} \\
\text { Total } \\
(\mathrm{ppm})\end{array}$ & $\begin{array}{c}\text { Total } \\
\text { polyphenols* }\end{array}$ & TAAE $* *$ \\
\hline \multirow{2}{*}{$\mathbf{C W}$} & 11.23 & 3.42 & 5.96 & 0.48 & $8.5^{\mathrm{a}, \mathrm{b}}$ & $31.0 \mathrm{~b}$ & 1017.5 & 11.74 \\
\hline & 0.25 & 0.20 & 0.40 & 0.08 & 0.71 & 1.51 & 38.7 & 1.21 \\
\hline \multirow{2}{*}{ AFA3 } & 11.21 & 3.16 & 5.79 & 0.59 & $12.5^{\mathrm{c}}$ & $32.0 \mathrm{~b}$ & 987.6 & 10.42 \\
\hline & 0.15 & 0.22 & 0.35 & 0.07 & 1.05 & 1.98 & 22.2 & 0.98 \\
\hline \multirow{2}{*}{ AFA6 } & 11.51 & 3.38 & 6.11 & 0.54 & $11.0^{\mathrm{c}}$ & $29.0 \mathrm{~b}$ & 995.3 & 11.02 \\
\hline & 0.32 & 0.31 & 0.36 & 0.05 & 0.56 & 2.10 & 19.7 & 0.78 \\
\hline \multirow{2}{*}{ MFA3 } & 11.18 & 3.32 & 5.88 & 0.50 & $11.5^{\mathrm{c}}$ & $33.5 \mathrm{~b}$ & 1003.8 & 9.89 \\
\hline & 0.24 & 0.19 & 0.41 & 0.07 & 0.87 & 1.98 & 36.9 & 1.02 \\
\hline \multirow{2}{*}{ MFA6 } & 11.20 & 3.33 & 5.92 & 0.54 & $8.5^{\mathrm{a}, \mathrm{b}}$ & $24.0 \mathrm{a}$ & 1054.4 & 10.12 \\
\hline & 0.32 & 0.25 & 0.38 & 0.08 & 0.75 & 1.78 & 36.2 & 0.96 \\
\hline \multirow{2}{*}{ PFA3 } & 11.55 & 3.31 & 5.89 & 0.60 & $7.0^{\mathrm{a}}$ & $26.0 \mathrm{a}$ & 999.5 & 12.10 \\
\hline & 0.31 & 0.24 & 0.28 & 0.09 & 0.98 & 1.55 & 25.8 & 1.65 \\
\hline \multirow{2}{*}{ PFA6 } & 11.45 & 3.29 & 5.96 & 0.59 & $9.0^{\mathrm{b}}$ & $33.5 b$ & 1035.0 & 11.01 \\
\hline & 0.33 & 0.18 & 0.36 & 0.06 & 0.65 & 2.14 & 45.3 & 0.89 \\
\hline
\end{tabular}

Different indexes $(a, b, c \ldots)$ in the same column indicate statistically significant differences among different wines according to the StudentNewman-Keuls test $(\mathrm{P}<0.05)$

* $\mathrm{mg} / \mathrm{L}$ as gallic acid

** $\mathrm{mmol} / \mathrm{L}$ of Trolox equivalents

\section{Monomeric anthocyanins and pyranoanthocyanins}

The monomeric anthocyanins of Moravia Agria wines were the expected 3-glucoside (3-glc), 3-(6"-acetyl)-glucoside (3-acglc), and 3-(6"-p-coumaroyl)-glucoside (3-cmglc) derivatives of delphinidin, cyanidin, petunidin, peonidin, and malvidin (dp, cy, pt, pn, and mv respectively), together with small amounts of the 3-(6"-caffeoyl)-glucoside (3-cfglc) derivative of only malvidin (Table 2). The profiles of monomeric anthocyanins of all the different wines studied made with Moravia Agria variety from Castilla-La Mancha were clearly dominated by malvidin derivatives, followed by peonidin, delphinidin and petunidin derivatives, as is common for most widespread $V$. vinifera varieties (Hermosín-Gutiérrez \& García-Romero, 2004). Nonacylated anthocyanins accounted for 87 to $89 \%$ of the total anthocyanin pool, whereas the proportions of acetylated, $p$-coumaroylated and caffeoylated anthocyanins were around of 5.5 to $7.5 \%, 5.5$ to $6.8 \%$ and $<0.3 \%$, respectively. The most important individual contributor to Moravia Agria red wines was mv-3-glc (range 65.47 to $69.49 \%$ ), followed by pn-3-glc (range 7.85 to $9.78 \%$ ), dp-3-glc (range 4.18 to $5.81 \%$ ) and pt-3-glc (range 5.53 to $7.48 \%$ ). The latter results are in agreement with the well-known differences found between the anthocyanin profiles of grapes and their respective wines, since the anthocyanin profile of Moravia Agria grapes has been reported as 80 to $82 \%$ of non-acylated anthocyanins ( 49 to $51 \%$ of mv-3-glc), around 2 to $5 \%$ of acetylated anthocyanins, 12 to $17 \%$ of $p$-coumaroylated anthocyanins, and 0.6 to $0.7 \%$ of caffeoylated anthocyanins (Gómez Gallego et al., 2012b).

The treatment with oak chips generally did not introduce changes in the main contributors to the anthocyanin profiles (non-acylated and acetylated anthocyanins) and only slight differences were found for some of the minor compounds (individual percentages lower than $2.5 \%$ ), as cy-3-glc, pn3 -acglc and $p$-coumaroylated derivatives (pn-3-cmglc and both isomer configurations of mv-3-cmglc). With regard to the anthocyanin content, the values found for all Moravia Agria wines, both control and chip-treated wines, ranged within the usual values reported for red wines (SánchezMoreno et al., 2003; Kallithraka et al., 2006; Gómez-Alonso et al., 2007), and only MFA wines resulted in significant lower values. The aforementioned results were in agreement with those previously reported for other wines elaborated with the addition of oak chips during alcoholic fermentation (Soto Vázquez et al., 2010), or in the post-fermentative phase (Sartini et al., 2007; Cejudo-Bastante et al., 2011a; 2011b; González-Sáiz et al., 2014). In contrast, we did not find reference data dealing with oak chip addition during the development of malolactic fermentation.

Grape monomeric anthocyanins are involved in reactions just after their transfer to fermenting must and also over wine ageing, thus giving rise to new anthocyanin-derived polymeric red pigments (the tannin-anthocyanin adducts, mediated or not by acetaldehyde linkage), and also to nonpolymeric pyranoanthocyanins (Monagas \& Bartolomé, 2009). Table 3 shows the molar profiles of vitisin-like and hydroxyphenyl-type series of pyranoanthocyanins found in Moravia Agria wines, as well as the total concentration of these kinds of compounds for each oak-treated wine and the control wine. Vitisin-type pyranoanthocyanins dominated over hydroxyphenyl-type ones in all wines, being vitisin A (10-carboxy-pyranomalvidin 3-glucoside), the major pyranoanthocyanin found in every wine and accounting for 
TABLE 2

Anthocyanin profiles (percentages of each individual anthocyanin over the total amount) and total amount of anthocyanins (mean value and SD; $n=2$ ).

\begin{tabular}{|c|c|c|c|c|c|c|c|c|c|c|c|c|c|c|}
\hline \multirow{2}{*}{$\begin{array}{l}\text { Anthocyanin } \\
\text { dp-3-glc }\end{array}$} & \multicolumn{2}{|c|}{$\mathrm{CW}$} & \multicolumn{2}{|c|}{ AFA3 } & \multicolumn{2}{|c|}{ AFA6 } & \multicolumn{2}{|c|}{ MFA3 } & \multicolumn{2}{|c|}{ MFA6 } & \multicolumn{2}{|c|}{ PFA3 } & \multicolumn{2}{|c|}{ PFA6 } \\
\hline & 5.55 & 0.91 & 5.12 & 0.75 & 5.69 & 0.78 & 5.81 & 0.91 & 5.79 & 0.79 & 5.18 & 0.39 & 4.18 & 0.88 \\
\hline cy-3-glc & $0.471^{\mathrm{a}}$ & 0.23 & $1.06^{\mathrm{c}}$ & 0.14 & $1.49^{\mathrm{c}}$ & 0.32 & $1.30^{\mathrm{c}}$ & 0.41 & $0.935^{\mathrm{b}, \mathrm{c}}$ & 0.12 & $0.874^{\mathrm{a}, \mathrm{b}}$ & 0.08 & $0.663^{\mathrm{a}, \mathrm{b}}$ & 0.19 \\
\hline pt-3-glc & 5.53 & 0.84 & 5.59 & 0.95 & 5.72 & 0.44 & 5.42 & 0.69 & 7.48 & 1.35 & 6.04 & 0.66 & 6.13 & 0.22 \\
\hline pn-3-glc & 9.78 & 0.89 & 9.25 & 0.71 & 8.40 & 0.65 & 7.85 & 1.07 & 7.98 & 1.41 & 8.81 & 0.79 & 8.11 & 0.58 \\
\hline mv-3-glc & 65.86 & 2.74 & 66.34 & 0.98 & 66.99 & 0.74 & 68.60 & 1.24 & 65.47 & 2.15 & 66.43 & 1.14 & 69.49 & 2.31 \\
\hline dp-3-acglc & 1.19 & 0.17 & 1.40 & 0.22 & 1.13 & 0.12 & 1.15 & 0.09 & 1.403 & 0.25 & 1.05 & 0.15 & 1.16 & 0.09 \\
\hline cy-3-acglc & \multicolumn{2}{|c|}{$\operatorname{tr}$} & \multicolumn{2}{|c|}{$\operatorname{tr}$} & \multicolumn{2}{|c|}{$\operatorname{tr}$} & \multicolumn{2}{|c|}{$\operatorname{tr}$} & \multicolumn{2}{|c|}{$\operatorname{Tr}$} & \multicolumn{2}{|c|}{$\operatorname{tr}$} & \multicolumn{2}{|c|}{$\operatorname{tr}$} \\
\hline pt-3-acglc & 0.79 & 0.08 & 0.803 & 0.05 & 0.902 & 0.10 & 0.764 & 0.08 & 0.861 & 0.11 & 0.874 & 0.12 & 0.829 & 0.09 \\
\hline pn-3-acglc & $1.19^{\mathrm{a}}$ & 0.24 & $1.61^{\mathrm{a}, \mathrm{b}}$ & 0.29 & $1.35^{\mathrm{a}}$ & 0.12 & $1.15^{\mathrm{a}}$ & 0.09 & $1.871^{\mathrm{b}}$ & 0.15 & $1.75^{\mathrm{b}}$ & 0.17 & $1.03^{\mathrm{a}}$ & 0.17 \\
\hline mv-3-acglc & 3.17 & 0.34 & 3.01 & 0.21 & 2.71 & 0.31 & 2.67 & 0.29 & 2.993 & 0.15 & 3.06 & 0.19 & 2.82 & 0.38 \\
\hline dp-3-cmglc & 1.03 & 0.07 & 1.01 & 0.09 & 1.08 & 0.11 & 0.96 & 0.07 & 0.935 & 0.07 & 0.971 & 0.09 & 0.995 & 0.10 \\
\hline cy-3-cmglc & \multicolumn{2}{|c|}{$\operatorname{tr}$} & \multicolumn{2}{|c|}{ 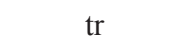 } & \multicolumn{2}{|c|}{$\operatorname{tr}$} & \multicolumn{2}{|c|}{$\operatorname{tr}$} & \multicolumn{2}{|c|}{$\operatorname{Tr}$} & \multicolumn{2}{|c|}{$\operatorname{tr}$} & \multicolumn{2}{|c|}{$\operatorname{tr}$} \\
\hline pt-3-cmglc & 0.364 & 0.06 & 0.281 & 0.03 & 0.25 & 0.06 & 0.229 & 0.08 & 0.281 & 0.05 & 0.324 & 0.04 & 0.332 & 0.04 \\
\hline pn-3-cmglc & $1.42^{\mathrm{b}}$ & 0.08 & $1.03^{\mathrm{a}}$ & 0.09 & $0.902^{\mathrm{a}}$ & 0.11 & $0.860^{\mathrm{a}}$ & 0.15 & $0.935^{\mathrm{a}}$ & 0.09 & $0.918^{\mathrm{a}}$ & 0.10 & $0.995^{\mathrm{a}}$ & 0.08 \\
\hline mv-3-cis-cmglc & $0.95^{\mathrm{a}}$ & 0.08 & $1.01^{\mathrm{a}}$ & 0.04 & $1.35^{\mathrm{b}}$ & 0.03 & $0.955^{\mathrm{a}}$ & 0.07 & $1.029^{\mathrm{a}}$ & 0.06 & $1.31^{\mathrm{b}}$ & 0.13 & $0.995^{\mathrm{a}}$ & 0.08 \\
\hline mv-3-trans-cmglc & $2.42^{\mathrm{b}}$ & 0.11 & $2.29^{\mathrm{b}}$ & 0.10 & $1.81^{\mathrm{a}}$ & 0.12 & $2.10^{\mathrm{a}, \mathrm{b}}$ & 0.12 & $1.871^{\mathrm{a}}$ & 0.16 & $2.18^{\mathrm{a}, \mathrm{b}}$ & 0.13 & $1.99^{\mathrm{a}, \mathrm{b}}$ & 0.15 \\
\hline mv-3-cfglc & 0.285 & 0.06 & 0.201 & 0.07 & 0.226 & 0.06 & 0.191 & 0.07 & 0.187 & 0.07 & 0.219 & 0.07 & 0.282 & 0.05 \\
\hline Total Anthocyanin* & $327.9^{b}$ & 13.21 & $311.2^{\mathrm{b}}$ & 10.62 & $324.8^{\mathrm{b}}$ & 17.24 & $289.5^{\mathrm{a}}$ & 8.24 & $278.4^{\mathrm{a}}$ & 10.39 & $319.1^{\mathrm{b}}$ & 10.78 & $331.2^{b}$ & 10.44 \\
\hline
\end{tabular}

Different indexes $(a, b, c . .$.$) in the same row indicate significant differences among different wines according to the Student-Newman-Keuls$ test $(\mathrm{P}<0.05)$. dp, delphinidin; cy, yaniding; pt, petunidin; pn, peonidin; mv, malvidin; 3-glc, 3-glucoside; 3-acglc, 3-(6"-acetyl)glucoside; 3-cmglc, 3-(6"-p-coumaroyl)glucoside (trans isomer if not indicated); 3-cfglc, 3-(6"-caffeoyl)glucoside; nd, not detected.

$* \mathrm{mg} / \mathrm{L}$, as malvidin 3-glucoside equivalents.

concentrations within levels reported usually (1.81 to 5.64 mg/L) (Rentzsch et al., 2010; Schwarz et al., 2010). The formation of vitisin-type pyranoanthocyanins is related to yeast metabolites (pyruvic acid for vitisin $A$ and acetaldehyde for vitisin B). Vitisin A is only produced during alcoholic fermentation, whereas vitisin B can also be formed during oxidative wine ageing (barrel ageing and micro-oxygenated wine ageing), and its concentration tends to decrease over ageing (Blanco-Vega et al., 2011). Our results suggest that the fate of vitisin-like pyranoanthocyanin is accelerated by oak chip addition $(2.84$ to $3.73 \mathrm{mg} / \mathrm{L}$, vs. $8.33 \mathrm{mg} / \mathrm{L}$ in $\mathrm{CW}$ ), especially when it is made during the development of malolactic fermentation (MFA wines). Slight decreases in B-type vitisins and near maintenance of the levels of A-type vitisins have been reported for Petit Verdot and Merlot wines elaborated with chip addition after micro-oxygenation and malolactic fermentation (Cejudo-Bastante et al., 2011a, 2011b). Therefore, the addition of oak chips to red wine during malolactic fermentation seems to cause a decrease in all types of monomeric anthocyanins and vitisin-like pyranoanthocyanins. It is very likely that the reason for the loss of non-polymeric red pigments promoted by oak chip addition is associated with the longer duration of treatment during malolactic fermentation (around three weeks of chip maceration) compared to that of other treatments (seven to 10 days of chip maceration).

With regard to hydroxyphenyl-pyranoanthocyanins, the main compound was 10-(4"'-monohydroxy)phenylpyranomalvidin 3-glucoside (10-MHP-pyrmv-3-glc, formed by the reaction of mv-3-glc with $p$-coumaric acid) in all studied wines, followed by 10-(3", 4 ,"'-dihydroxy)phenylpyranomalvidin 3-glucoside (10-DHP-pyrmv-3-glc, also known as pinotin $\mathrm{A}$, formed by the reaction of $\mathrm{mv}-3$-glc with caffeic acid), in agreement with data reported for young red wines (Rentzsch et al., 2010). Wines to which oak chips were added presented lower quantities of 10-MPH-pyrmv-3glc and 10-DHP-pyrmv-3-glc than the control wine.

In summary, the results discussed above suggest that the oak chip treatment led to less favourable results in terms of the content of anthocyanin-related pigments; when it was done only during malolactic fermentation, a remarkable decrease in the total content of monomeric anthocyanins was observed, although the characteristic anthocyanin profile remained practically unchanged; in addition, and closely connected to the loss of monomeric anthocyanins, parallel decreases in the concentrations of pyranoanthocyanins developed.

\section{Flavonols}

The expected pool of flavonol glycosides and their hydrolysisreleased free aglycones (Castillo-Muñoz et al., 2007) was found in all the studied Moravia Agria red wines. For a comprehensive statistical treatment of the data concerning flavonol profiles, all the flavonols were grouped on the basis of the common type of flavonoid structure involved in an aglycon and its respective 3-glycosides, leading to six aglycon-type flavonol groups. Table 4 shows the aglycontype flavonol profiles together with the total concentration 
TABLE 3

Individual and total pyranoanthocyanin amounts (mean value and $\mathrm{SD} ; \mathrm{n}=2$ ).

\begin{tabular}{|c|c|c|c|c|c|c|c|c|c|c|c|c|c|c|}
\hline \multirow{2}{*}{$\begin{array}{l}\text { Pyranoanthocyanin } \\
\text { vitisin } A^{*}\end{array}$} & \multicolumn{2}{|c|}{$\mathbf{C W}$} & \multicolumn{2}{|c|}{ AFA3 } & \multicolumn{2}{|c|}{ AFA6 } & \multicolumn{2}{|c|}{ MFA3 } & \multicolumn{2}{|c|}{ MFA6 } & \multicolumn{2}{|c|}{ PFA3 } & \multicolumn{2}{|c|}{ PFA6 } \\
\hline & $5.64^{\mathrm{b}}$ & 0.25 & $2.35^{\mathrm{a}}$ & 0.21 & $2.29^{\mathrm{a}}$ & 0.27 & $1.81^{\mathrm{a}}$ & 0.31 & $1.89^{\mathrm{a}}$ & 0.15 & $2.25^{\mathrm{a}}$ & 0.22 & $2.25^{\mathrm{a}}$ & 0.29 \\
\hline vitisin $B^{*}$ & $2.69^{\mathrm{c}}$ & 0.15 & $1.37^{\mathrm{a}, \mathrm{b}}$ & 0.27 & $1.43^{\mathrm{b}}$ & 0.17 & $1.02^{\mathrm{a}}$ & 0.19 & $1.03^{\mathrm{a}}$ & 0.10 & $1.21^{\mathrm{a}, \mathrm{b}}$ & 0.13 & $1.46^{\mathrm{b}}$ & 0.16 \\
\hline total vitisins* & $8.33^{\mathrm{c}}$ & 0.32 & $3.73^{\mathrm{b}}$ & 0.19 & $3.72^{\mathrm{b}}$ & 0.25 & $2.84^{\mathrm{a}}$ & 0.29 & $2.92^{\mathrm{a}}$ & 0.16 & $3.46^{\mathrm{b}}$ & 0.24 & $3.71^{\mathrm{b}}$ & 0.23 \\
\hline 10-MHP-pyrmv-3-glc** & $0.260^{\mathrm{e}}$ & 0.12 & $0.042^{c}$ & 0.08 & $0.044^{\mathrm{c}}$ & 0.09 & $0.011^{\mathrm{a}}$ & 0.05 & $0.010^{\mathrm{a}}$ & 0.03 & $0.024^{\mathrm{b}}$ & 0.07 & $0.076^{\mathrm{d}}$ & 0.10 \\
\hline 10-MHP-pyrmv-3-cmgle** & $0.736^{\mathrm{d}}$ & 0.10 & $0.117^{\mathrm{c}}$ & 0.05 & $0.093^{\mathrm{b}}$ & 0.02 & $0.044^{\mathrm{a}}$ & 0.01 & $0.039^{\mathrm{a}}$ & 0.01 & $0.059^{\mathrm{a}}$ & 0.02 & $0.179^{\mathrm{c}}$ & 0.02 \\
\hline 10-DHP-pyrmv-3-glc** & $0.088^{c}$ & 0.01 & $0.025^{\mathrm{a}}$ & 0.02 & $0.028^{\mathrm{a}}$ & 0.02 & $0.013^{\mathrm{a}}$ & 0.02 & $0.010^{\mathrm{a}}$ & 0.01 & $0.018^{\mathrm{a}}$ & 0.01 & $0.042^{\mathrm{b}}$ & 0.02 \\
\hline 10-DHP-pyrmv-3-cmglc *** & $0.100^{\mathrm{b}}$ & 0.01 & $0.024^{\mathrm{a}}$ & 0.01 & $0.023^{\mathrm{a}}$ & 0.01 & $0.026^{\mathrm{a}}$ & 0.01 & $0.010^{\mathrm{a}}$ & 0.01 & $0.017^{\mathrm{a}}$ & 0.01 & $0.037^{\mathrm{a}}$ & 0.02 \\
\hline $\begin{array}{l}\text { total hydroxyphenyl- } \\
\text { pyranoanthocyanins } * *\end{array}$ & $1.18^{\mathrm{e}}$ & 0.11 & $0.208^{c}$ & 0.09 & $0.189^{c}$ & 0.03 & $0.093^{\mathrm{a}, \mathrm{b}}$ & 0.02 & $0.069^{\mathrm{a}}$ & 0.01 & $0.118^{\mathrm{b}}$ & 0.02 & $0.333^{\mathrm{d}}$ & 0.03 \\
\hline
\end{tabular}

Different indexes $(\mathrm{a}, \mathrm{b}, \mathrm{c} . .$.$) in the same row indicate significant differences among different wines according to the Student-Newman-Keuls$ test $(\mathrm{P}<0.05)$; nd, not detected. Pyrpn, pyranopeonidin; pyrmv, pyranomalvidin; 3-glc, 3-glucoside; 3-cmglc, 3-(6"-p-coumaroyl)glucoside; 10-MHP, 10-(4"'-monohydroxy)phenyl; 10-DHP, 10-(3" ",4"'-dihydroxy)phenyl. * mg/L, as vitisin A equivalents ** mg/L, as 10-DHPpyrmv-3-glc equivalents.

of flavonols.

The main flavonol families were those of myricetin and quercetin, with each one accounting for 31.67 to $35.82 \%$ and 19.86 to $27.49 \%$ respectively, followed by those of isorhamnetin (16.26 to $19.59 \%$ ), laricitrin (12.26 to $14.18 \%$ ), kaempferol (5.88 to $7.32 \%$ ) and syringetin (3.32 to $9.55 \%$ ). In comparison to the reported flavonol profile of Moravia Agria grapes (Gómez Gallego et al., 2012b), the percentage contributions of quercetin-type flavonols decreased significantly ( 40.52 to $57.27 \%$ in grapes), and those of isorahmnetin and syringetin increased (4.38 to $5.37 \%$ and 2.83 to $7.53 \%$ respectively in grapes), and these changes were significantly higher than in the case of the control wines. The remarkable differences showed by the aglycon-type flavonol profile of Moravia Agria wines with regard to their respective grapes also affected the percentages of myricetin- (23.64 to $26.65 \%$ in grapes), laricitrin- (12.26 to $14.18 \%$ in grapes) and, to a lesser extent, kaempferol-type, flavonols (5.88 to $7.32 \%$ in grapes). However, for the latter types of flavonols, non-significant differences were found between the control and treated wines. The aforementioned result suggest that oak chips could exert some kind of effect on physical interactions (e.g. insolubilisation and precipitation) and/or chemical reactions (e.g. flavonol 3-glycoside hydrolysis and flavonol oxidation) involving wine flavonols.

The total flavonol content of wines could be affected by many factors, such as grape cultivar, viticultural conditions and winemaking process (Price et al., 1995; Schwarz et al., 2005; Castillo-Muñoz et al., 2007). In general, the addition of oak chips to Moravia Agria wine led to a significantly higher total content of flavonols (Table 4) when oak chips were added during or after the malolactic fermentation (MFA and PFA wines). In other words, it can be suggested that the absence of oak chips, or their early addition during the first of the two fermentation processes involved in red wine elaboration, led to lower total amounts of flavonols and, as discussed previously, to quercetin-and isorhamnetin-type flavonols as the main affected compounds. Nevertheless, all Moravia Agria wines accounted for flavonol levels that could be considered as normal (mean value, 131.88 to 203.41 $\mathrm{mmol} / \mathrm{L}$ ), since the reported mean values for other red wines range from 81 to $274 \mathrm{mmol} / \mathrm{L}$ (Hermosín-Gutiérrez et al., 2011).

\section{Flavan-3-ols}

Three of the most common flavan-3-ol monomers were found in the studied red wines: $(+)$-catechin, (-)-epicatechin and (-)-epigallocatechin (Sánchez-Moreno et al., 2003; GómezAlonso et al., 2007). The results are shown in Table 5. As expected, the flavan-3-ol monomers occurring the most in all wines were $(+)$-catechin (mean values within 18.44 to $23.67 \mathrm{mg} / \mathrm{L}$ ) and (-)-epicatechin (mean values within 22.65 to $28.11 \mathrm{mg} / \mathrm{L}$ ), followed by (-)-epigallocatechin (mean values within 3.76 to $6.24 \mathrm{mg} / \mathrm{L}$ ). According to the results, the addition of oak chips introduced only a slight decrease in the concentrations of (-)-epicatechin and (-)-epigallocatechin when it was done after alcoholic fermentation.

\section{Hydroxycinnamic acid derivatives (HCAD)}

The hydroxycinnamic acid derivatives (HCAD) found in all the studied wines were the expected grape-native hydroxycinnamoyl-tartaric acids (caftaric and coutaric acids), and some of their reaction products that are formed in wine (Table 6), that is, the respective free hydroxycinnamic acids released by hydrolysis (caffeic and $p$-coumaric acids respectively) and their ethyl esters (ethyl caffeate and ethyl coumarate).

No large differences were found between the control wine $(\mathrm{CW})$ and the wines to which oak chips were added during alcoholic fermentation (AFA wines) and the wines to which oak chips were added during malolactic fermentation (MFA wines). However, the wines to which oak chips were added after both fermentations (PFA wines) were significantly different from the rest of the wines with respect to their hydroxycinnamic acid derivative profiles, mainly connected to the highest extent of the aforementioned process of hydrolysis ( 17.43 and $17.79 \%$ respectively). The percentage of ethyl esters did not change significantly in these cases in 
TABLE 4

Aglycon-type flavonol profiles (molar percentages) and total flavonol concentrations (mean value and SD; $\mathrm{n}=2$ ).

\begin{tabular}{|c|c|c|c|c|c|c|c|c|c|c|c|c|c|c|}
\hline \multirow{2}{*}{$\begin{array}{l}\text { Flavonol } \\
\text { myricetin-type }\end{array}$} & \multicolumn{2}{|c|}{$\mathbf{C W}$} & \multicolumn{2}{|c|}{ AFA3 } & \multicolumn{2}{|c|}{ AFA6 } & \multicolumn{2}{|c|}{ MFA3 } & \multicolumn{2}{|c|}{ MFA6 } & \multicolumn{2}{|c|}{ PFA3 } & \multicolumn{2}{|c|}{ PFA6 } \\
\hline & 32.91 & 0.91 & 32.30 & 1.12 & 35.82 & 1.84 & 31.67 & 1.43 & 33.77 & 0.82 & 32.38 & 1.02 & 30.33 & 2.41 \\
\hline quercetin-type & $19.86^{\mathrm{a}}$ & 1.21 & $23.20^{\mathrm{b}}$ & 1.32 & $21.50^{\mathrm{a}, \mathrm{b}}$ & 1.51 & $24.22^{\mathrm{b}}$ & 1.98 & $22.52^{b}$ & 1.61 & $25.36^{\mathrm{b}, \mathrm{c}}$ & 2.14 & $27.49^{c}$ & 1.34 \\
\hline laricitrin-type & 14.10 & 0.91 & 14.57 & 0.82 & 12.26 & 1.04 & 13.47 & 0.81 & 14.18 & 0.99 & 12.84 & 0.81 & 13.36 & 0.95 \\
\hline kaempferol-type & 7.32 & 0.72 & 6.36 & 0.65 & 5.96 & 0.72 & 5.91 & 0.84 & 5.88 & 0.71 & 6.84 & 0.74 & 6.54 & 0.61 \\
\hline $\begin{array}{l}\text { isorhamnetin- } \\
\text { type }\end{array}$ & $16.26^{\mathrm{a}}$ & 0.51 & $18.45^{\mathrm{b}}$ & 0.58 & $18.37^{\mathrm{b}}$ & 0.21 & $18.29^{\mathrm{b}}$ & 0.22 & $19.59^{\mathrm{b}}$ & 0.77 & $18.78^{b}$ & 0.72 & $18.96^{\mathrm{b}}$ & 0.69 \\
\hline syringetin-type & $9.55^{\mathrm{e}}$ & 0.45 & $5.11^{\mathrm{c}}$ & 0.42 & $6.09^{d}$ & 0.35 & $6.43^{\mathrm{d}}$ & 0.39 & $4.05^{\mathrm{b}}$ & 0.25 & $3.78^{\mathrm{a}, \mathrm{b}}$ & 0.26 & $3.32^{\mathrm{a}}$ & 0.27 \\
\hline total flavonols* & $131.88^{\mathrm{a}}$ & 11.31 & $142.12^{\mathrm{a}}$ & 11.12 & $139.77^{\mathrm{a}}$ & 9.34 & $166.13^{\mathrm{b}, \mathrm{c}}$ & 10.41 & $151.24^{b}$ & 12.24 & $174.34^{\mathrm{c}}$ & 9.14 & $203.41^{\mathrm{d}}$ & 12.52 \\
\hline
\end{tabular}

TABLE 5

Flavan-3-ol profile concentrations [mean value (mg/L) and SD].

\begin{tabular}{|c|c|c|c|}
\hline & $(+)$-Catechin & (-)-Epicatechin & (-)-Epigallocatechin \\
\hline \multirow{2}{*}{ CW } & $23.67^{b}$ & $28.11^{\mathrm{c}}$ & $6.24^{c}$ \\
\hline & 1.24 & 1.34 & 0.75 \\
\hline \multirow{2}{*}{ AFA3 } & $21.10^{\mathrm{b}}$ & $25.58^{\mathrm{b}}$ & $5.44^{b}$ \\
\hline & 1.41 & 1.12 & 0.41 \\
\hline \multirow{2}{*}{ AFA6 } & $22.39^{b}$ & $25.70^{\mathrm{b}}$ & $5.78^{\mathrm{b}, \mathrm{c}}$ \\
\hline & 1.03 & 0.98 & 0.48 \\
\hline \multirow{2}{*}{ MFA3 } & $18.44^{\mathrm{a}}$ & $24.51^{\mathrm{a}, \mathrm{b}}$ & $4.09^{\mathrm{a}}$ \\
\hline & 0.78 & 1.14 & 0.68 \\
\hline \multirow{2}{*}{ MFA6 } & $21.47^{b}$ & $22.65^{\mathrm{a}}$ & $3.76^{\mathrm{a}}$ \\
\hline & 1.15 & 1.13 & 0.53 \\
\hline \multirow{2}{*}{ PFA3 } & $21.94^{b}$ & $24.92^{\mathrm{a}, \mathrm{b}}$ & $4.76^{\mathrm{a}, \mathrm{b}}$ \\
\hline & 0.99 & 0.97 & 0.75 \\
\hline \multirow{2}{*}{ PFA6 } & $21.01^{\mathrm{b}}$ & $23.12^{\mathrm{a}}$ & $4.51^{\mathrm{a}, \mathrm{b}}$ \\
\hline & 1.11 & 1.05 & 0.52 \\
\hline
\end{tabular}

Different indexes $(a, b, c \ldots)$ in the same column indicate statistically significant differences among different wines according to the StudentNewman-Keuls test $(\mathrm{P}<0.05)$

TABLE 6

Hydroxycinnamic acid derivative (HCAD) profiles (molar percentages) and total amount of HCAD (mean value and SD; $n=2$ ).

\begin{tabular}{lcccccccccccccccc}
\hline \multicolumn{1}{c}{ HCAD } & \multicolumn{2}{c}{ CW } & \multicolumn{3}{c}{ AFA3 } & \multicolumn{2}{c}{ AFA6 } & \multicolumn{2}{c}{ MFA3 } & \multicolumn{2}{c}{ MFA6 } & \multicolumn{2}{c}{ PFA3 } & \multicolumn{1}{c}{ PFA6 } \\
\hline caftaric acid & $60.95^{\mathrm{b}}$ & 1.34 & $61.37^{\mathrm{b}}$ & 1.98 & $62.80^{\mathrm{b}}$ & 1.74 & $62.28^{\mathrm{b}}$ & 1.35 & $60.01^{\mathrm{b}}$ & 2.75 & $55.84^{\mathrm{a}}$ & 1.21 & $54.04^{\mathrm{a}}$ & 1.15 \\
coutaric acid & 12.06 & 1.07 & 11.94 & 1.11 & 10.76 & 0.89 & 11.34 & 0.99 & 12.92 & 1.13 & 11.17 & 0.79 & 10.30 & 1.12 \\
caffeic acid & $18.17^{\mathrm{a}}$ & 0.88 & $20.92^{\mathrm{a}}$ & 1.79 & $19.93^{\mathrm{a}}$ & 0.96 & $18.22^{\mathrm{a}}$ & 1.41 & $19.82^{\mathrm{a}}$ & 1.45 & $23.81^{\mathrm{b}}$ & 0.95 & $24.60^{\mathrm{b}}$ & 0.66 \\
$p_{\text {-coumaric acid }}$ & $4.75^{\mathrm{a}}$ & 0.74 & $3.69^{\mathrm{a}}$ & 0.51 & $3.98^{\mathrm{a}}$ & 0.61 & $4.32^{\mathrm{a}}$ & 0.96 & $4.76^{\mathrm{a}}$ & 0.75 & $6.25^{\mathrm{b}}$ & 0.62 & $7.49^{\mathrm{b}}$ & 0.87 \\
ethyl caffeate & $1.26^{\mathrm{b}}$ & 0.29 & $0.99^{\mathrm{a}, \mathrm{b}}$ & 0.31 & $1.01^{\mathrm{b}}$ & 0.15 & $1.11^{\mathrm{b}}$ & 0.26 & $0.55^{\mathrm{a}}$ & 0.15 & $0.83^{\mathrm{a}, \mathrm{b}}$ & 0.18 & $0.72^{\mathrm{a}, \mathrm{b}}$ & 0.17 \\
ethyl coumarate & $2.82^{\mathrm{c}}$ & 0.36 & $1.09^{\mathrm{a}}$ & 0.42 & $1.51^{\mathrm{a}, \mathrm{b}}$ & 0.29 & $2.73^{\mathrm{d}}$ & 0.46 & $1.95^{\mathrm{b}}$ & 0.15 & $2.10^{\mathrm{a}, \mathrm{b}, \mathrm{c}}$ & 0.62 & $2.84^{\mathrm{c}}$ & 0.44 \\
total amount* & 104.37 & 10.40 & 90.37 & 7.45 & 99.92 & 6.35 & 97.23 & 6.58 & 98.25 & 8.81 & 92.15 & 7.33 & 90.72 & 9.87 \\
caffeic-type & $80.38^{\mathrm{a}, \mathrm{b}}$ & 1.72 & $83.28^{\mathrm{b}}$ & 1.29 & $83.74^{\mathrm{b}}$ & 1.81 & $81.61^{\mathrm{a}, \mathrm{b}}$ & 1.41 & $80.37^{\mathrm{a}}$ & 0.55 & $80.48^{\mathrm{a}}$ & 0.42 & $79.36^{\mathrm{a}}$ & 1.68 \\
$p_{\text {-coumaric-type }}$ & $19.62^{\mathrm{a}, \mathrm{b}}$ & 1.21 & $16.72^{\mathrm{a}}$ & 1.34 & $16.25^{\mathrm{a}}$ & 1.76 & $18.39^{\mathrm{a}, \mathrm{b}}$ & 1.45 & $19.63^{\mathrm{a}, \mathrm{b}}$ & 1.33 & $19.52^{\mathrm{a}, \mathrm{b}}$ & 1.61 & $20.64^{\mathrm{b}}$ & 1.22 \\
\% hydrolysis** & $16.80^{\mathrm{a}, \mathrm{b}}$ & 0.81 & $15.63^{\mathrm{a}}$ & 0.81 & $14.74^{\mathrm{a}}$ & 1.38 & $15.66^{\mathrm{a}}$ & 0.72 & $17.67^{\mathrm{a}, \mathrm{b}}$ & 1.71 & $17.43^{\mathrm{b}}$ & 0.77 & $17.79^{\mathrm{b}}$ & 0.82 \\
\% ethyl esters & $4.08^{\mathrm{b}}$ & 0.67 & $2.08^{\mathrm{a}}$ & 0.92 & $2.52^{\mathrm{a}}$ & 0.53 & $3.84^{\mathrm{a}, \mathrm{b}}$ & 0.86 & $2.51^{\mathrm{a}}$ & 0.51 & $2.92^{\mathrm{a}}$ & 0.35 & $3.56^{\mathrm{a}, \mathrm{b}}$ & 0.68 \\
\hline
\end{tabular}

Different indexes $(\mathrm{a}, \mathrm{b}, \mathrm{c} . .$.$) in the same row indicate significant differences among different wines according to the Student-Newman-Keuls$ test $(\mathrm{P}<0.05)$.

$* \mathrm{mmol} / \mathrm{L} ; * *$ total sum of percentages of free hydroxycinnamic acids (caffeic and $p$-coumaric acids) and their ethyl esters 
respect to the control wine $(\mathrm{CW})$. No significant differences were found in the amounts of HCAD (range: 90.72 to 104.37 $\mathrm{mmol} / \mathrm{L})$. The amounts of added oak chips generally did not introduce remarkable changes in the aforementioned differences due to treatment timing.

\section{Resveratrol-monomer stilbenes}

The results dealing with stilbene monomers based on resveratrol are shown in Table 7. Piceid is the main naturally occurring form of resveratrol found in grapes and it is partially hydrolysed during winemaking (Mattivi et al., 1995; Sun et al., 2006), giving rise to less soluble resveratrol. In addition, the trans isomers of both piceid and resveratrol can be transformed easily into their corresponding cis isomer under UV light, and such transformation is already present in grapes.

The concentrations of all resveratrol-based stilbenes in the control wine $(\mathrm{CW})$ were significantly higher than in wines with added oak chips. The total content of resveratrol (total sum of all resveratrol forms) varied depending upon the timing of the addition of oak chips. There were no significant differences between the results obtained with addition during alcoholic fermentation (AFA) and post-fermentation (PFA), but the total sum of all resveratrol forms was significantly lower than in the rest of the wines. Moreover, no differences were found from the doses of oak chips added $(3 \mathrm{~g} / \mathrm{L}$ or $6 \mathrm{~g} / \mathrm{L})$. Compared to the control wine $(\mathrm{CW})$, the addition of 3 and $6 \mathrm{~g} / \mathrm{L}$ of oak chips during the development of malolactic fermentation (MAF) reduced the total amount of resveratrol by more than $50 \%$. If only trans-resveratrol is considered, the contents were significantly higher in the CW than in the rest of wines. Finally, the control wines $(\mathrm{CW})$ presented higher proportions of trans isomers than wines treated with oak chips. More research is needed to ascertain the causes inducing a decrease in stilbene concentration in wines treated with oak chips.

In general, the total resveratrol content determined in these wines from the La Mancha region (13.79 to $26.75 \mathrm{mg} / \mathrm{L}$, as resveratrol equivalents) was higher than the values reported for other Spanish red wines (range of 0.60 to $8.0 \mathrm{mg} / \mathrm{L}$ ) (Lamuela-Raventós et al., 1995), some Italian wines (range of 0.17 to $10.79 \mathrm{mg} / \mathrm{L}$ ) (Mattivi et al., 1995), and wines from the United States, Australia and Argentina (average concentrations of 5 to $6 \mathrm{mg} / \mathrm{L})(\mathrm{Gu}$ et al., 1999). Therefore, it can be suggested that the studied wines elaborated with the Moravia Agria grape variety with the addition of oak chips could be described as wines with a high content of total resveratrol. Moreover, if only transresveratrol content is considered, these Moravia Agria wines still accounted for values closer to the upper limits of the aforementioned reported ranges for red wines.

\section{Chromatic characteristics and degree of co-pigmentation} The actual colour shown by a red wine is the result of a complex mixture of physical and chemical processes that are interconnected and mainly involve anthocyanins. Proton transfer and the hydration of anthocyanins, co-pigmentation complexes between anthocyanins and other phenolic compounds (usually non-coloured compounds), and the formation of anthocyanin-derived pigments are some of the known processes behind red wine colour. It therefore is difficult to predict the actual colour characteristics of red wines on the basis only of their anthocyanin content.

Table 8 shows the chromatic characteristics (CIELCh parameters) and contribution to the total wine colour at pH 3.6 of co-pigmented anthocyanins. All the analysed

\section{TABLE 7}

Resveratrol and piceid concentrations, total resveratrol and molar percentages of trans- and cis-isomers (mean value and SD; $\mathrm{n}=2)$.

\begin{tabular}{|c|c|c|c|c|c|c|c|}
\hline Wine & trans-piceid* & cis-piceid* & $\begin{array}{c}\text { trans- } \\
\text { resveratrol* }\end{array}$ & $\begin{array}{c}\text { cis- } \\
\text { resveratrol* }\end{array}$ & $\begin{array}{c}\% \text { total } \\
\text { trans-isomers }\end{array}$ & $\begin{array}{c}\% \text { total } \\
\text { cis-isomers }\end{array}$ & $\begin{array}{c}\text { total } \\
\text { resveratrol } * *\end{array}$ \\
\hline \multirow[t]{2}{*}{ CW } & $8.19^{b}$ & $35.53^{\mathrm{d}}$ & $30.59^{\mathrm{d}}$ & $21.93^{\mathrm{d}}$ & $40.29^{\mathrm{d}}$ & $59.71^{\mathrm{a}}$ & $26.75^{\mathrm{c}}$ \\
\hline & 0.75 & 0.91 & 0.79 & 1.01 & 1.12 & 1.11 & 1.25 \\
\hline \multirow[t]{2}{*}{ AFA3 } & $5.97^{\mathrm{a}}$ & $27.42^{\mathrm{b}}$ & $10.60^{\mathrm{b}, \mathrm{c}}$ & $12.85^{\mathrm{c}}$ & $29.15^{\mathrm{b}}$ & $70.85^{\mathrm{b}}$ & $15.80^{\mathrm{b}}$ \\
\hline & 0.54 & 0.97 & 0.93 & 0.92 & 1.33 & 1.19 & 0.88 \\
\hline \multirow[t]{2}{*}{ AFA6 } & $6.58^{\mathrm{a}}$ & $31.01^{\mathrm{c}}$ & $9.25^{\mathrm{b}}$ & $10.07^{b}$ & $27.82^{\mathrm{b}}$ & $72.18^{\mathrm{b}}$ & $15.82^{\mathrm{b}}$ \\
\hline & 0.74 & 1.05 & 0.79 & 0.93 & 0.87 & 1.41 & 1.09 \\
\hline \multirow[t]{2}{*}{ MFA3 } & $6.76^{\mathrm{a}}$ & $30.13^{\mathrm{c}}$ & $2.72^{\mathrm{a}}$ & $6.42^{\mathrm{a}}$ & $20.59^{a}$ & $79.41^{\mathrm{c}}$ & $12.79^{\mathrm{a}}$ \\
\hline & 0.81 & 1.92 & 0.59 & 0.57 & 1.15 & 1.32 & 1.0 \\
\hline \multirow[t]{2}{*}{ MFA6 } & $6.10^{\mathrm{a}}$ & $31.40^{\mathrm{c}}$ & $2.76^{\mathrm{a}}$ & $6.09^{\mathrm{a}}$ & $19.11^{\mathrm{a}}$ & $80.89^{c}$ & $12.88^{\mathrm{a}}$ \\
\hline & 0.34 & 0.95 & 0.57 & 0.97 & 1.06 & 1.12 & 0.98 \\
\hline \multirow[t]{2}{*}{ PFA3 } & $5.40^{\mathrm{a}}$ & $32.95^{\mathrm{c}}$ & $8.96^{\mathrm{b}}$ & $7.18^{\mathrm{a}}$ & $26.35^{\mathrm{b}}$ & $73.65^{\mathrm{b}}$ & $15.15^{\mathrm{b}}$ \\
\hline & 0.52 & 0.97 & 0.99 & 0.85 & 1.78 & 1.24 & 0.95 \\
\hline \multirow[t]{2}{*}{ PFA6 } & $5.46^{\mathrm{a}}$ & $22.14^{\mathrm{a}}$ & $11.98^{\mathrm{c}}$ & $11.52^{\mathrm{b}, \mathrm{c}}$ & $34.13^{\mathrm{c}}$ & $65.87^{\mathrm{b}}$ & $14.21^{\mathrm{b}}$ \\
\hline & 0.68 & 0.89 & 0.79 & 0.81 & 1.19 & 1.16 & 0.78 \\
\hline
\end{tabular}

Different indexes $(a, b, c \ldots)$ in the same column indicate significant differences among different wines according to the Student-NewmanKeuls test $(\mathrm{P}<0.05)$.

$* \mu \mathrm{mol} / \mathrm{L}$

** $\mathrm{mg} / \mathrm{L}$, as resveratrol equivalents 
TABLE 8

Chromatic characteristics (CIELCh parameters) and contribution to the total wine colour at $\mathrm{pH} 3.6$ of co-pigmented anthocyanins (\% co-pigmentation) (mean value and $\mathrm{SD} ; \mathrm{n}=2)$.

\begin{tabular}{|c|c|c|c|c|}
\hline & $L^{*}$ & $C^{*}$ & $h^{*}$ & $\%$ co-pigmentation \\
\hline \multirow[t]{2}{*}{$\mathbf{C W}$} & 79.81 & $12.1^{\mathrm{b}}$ & $359.2^{\mathrm{c}}$ & $4.86^{\mathrm{a}}$ \\
\hline & 2.22 & 1.07 & 1.50 & 0.34 \\
\hline \multirow[t]{2}{*}{ AFA3 } & 82.12 & $9.32^{\mathrm{a}}$ & $352.1^{\mathrm{b}}$ & $4.78^{a}$ \\
\hline & 1.15 & 0.59 & 1.15 & 0.54 \\
\hline \multirow[t]{2}{*}{ AFA6 } & 81.61 & $9.05^{\mathrm{a}}$ & $352.6^{\mathrm{b}}$ & $4.91^{\mathrm{a}, \mathrm{b}}$ \\
\hline & 1.75 & 0.87 & 1.41 & 0.75 \\
\hline \multirow[t]{2}{*}{ MFA3 } & 83.80 & $8.63^{\mathrm{a}}$ & $353.9^{\mathrm{b}}$ & $4.96^{\mathrm{a}, \mathrm{b}}$ \\
\hline & 1.93 & 1.05 & 0.96 & 0.69 \\
\hline \multirow[t]{2}{*}{ MFA6 } & 84.21 & $8.42^{\mathrm{a}}$ & $355.6^{\mathrm{b}}$ & $5.41^{\mathrm{b}}$ \\
\hline & 2.34 & 0.69 & 2.75 & 0.52 \\
\hline \multirow[t]{2}{*}{ PFA3 } & 84.33 & $8.38^{\mathrm{a}}$ & $349.5^{\mathrm{a}}$ & $5.53^{\mathrm{b}}$ \\
\hline & 2.36 & 0.87 & 0.98 & 0.47 \\
\hline \multirow[t]{2}{*}{ PFA6 } & 84.52 & $8.26^{\mathrm{a}}$ & $348.6^{\mathrm{a}}$ & $5.51^{\mathrm{b}}$ \\
\hline & 2.67 & 0.98 & 1.11 & 0.34 \\
\hline
\end{tabular}

Different indexes $(a, b, c .$.$) in the same column indicate statistically significant differences among different wines according to the Student-$ Newman-Keuls test $(\mathrm{P}<0.05)$

wines presented no significant differences in their values of luminosity $\left(L^{*}\right)$, so their colour intensity was not affected by treatment with oak chips. On the other hand, some significant differences were found in the chroma parameter $\left(\mathrm{C}^{*}\right)$. $\mathrm{CW}$ wines presented higher values of this parameter than the rest of wines, so the control wine showed more vivid colours than the other samples, which showed duller colours. The latter result suggests that the addition of oak chips during the winemaking process could decrease the colour purity of wines.

The co-pigmentation effect increased in direct proportion to the amount of chips applied, and the later the wood chips were applied, the greater was the co-pigmentation effect. This effect produced an increase in the contributions of purple tonalities (lower values of hue angle, $h^{*}$ ) (Boulton, 2001). In addition to co-pigmentation effects, the higher concentration of the red-orange vitisin-type pigments (Rentzsch et al., 2010) found in the CW wines (Table 3 ) could also contribute to the lower purplish nuances of the red colour shown by these wines (highest values of $h^{*}$ ).

\section{CONCLUSIONS}

We compared traditional winemaking with and without the addition of oak chips at different steps of processing, and the result was the similitude of wines with regard to their phenolic-related parameters. Only slightly significant differences in phenolic composition, antioxidant activity and chromatic characteristics were found between the Moravia Agria wines treated with oak chips and the control wine. However, the results suggest that oak chip addition during malolactic fermentation led to the more pronounced observed effects, especially a decrease in the content of non-polymeric red pigments, possibly due to the longer maceration time of oak chips at this stage of red wine elaboration. Therefore, using oak chips can improve the sensory score of red wines, with slight, but significant, changes in their phenolic composition and the properties related to them.

\section{LITERATURE CITED}

Arapitsas, P., Antonopoulos, A., Stefanou, E. \& Dourtoglou, V. G., 2004. Artificial aging of wines using oak chips. Food Chem. 86, 563-570.

Blanco-Vega, D., López-Bellido, F.J., Alía-Robledo, J.M. \& HermosínGutiérrez, I., 2011. HPLC-DAD-ESI-MS/MS characterization of pyranoanthocyanins pigments formed in model wine. J. Agric. Food Chem. 59, 9523-9531.

Boulton, R., 2001. The copigmentation of anthocyanins and its role in the color of red wine: A critical review. Am. J. Enol. Vitic. 52, 67-87.

Brand-Williams, W., Cuvelier M.E. \& Berset, C., 1995. Use of a free radical method to evaluate antioxidant activity. Lebensm. Wiss. Technol. 28, 25-30.

Castillo-Muñoz, N., Gómez-Alonso, S., García-Romero, E. \& HermosínGutiérrez, I., 2007. Flavonol profiles of Vitis vinifera red grapes and their single-cultivar wines. J. Agric. Food Chem. 55, 992-1002.

Castillo-Muñoz, N., Gómez-Alonso, S., García-Romero, E., Gómez, M.V., Velders, A.H. \& Hermosín-Gutiérrez, I., 2009. Flavonol 3-O-glycosides series of Vitis vinifera cv. Petit verdot red wine grapes. J. Agric. Food Chem. 57, 209-219.

Cejudo-Bastante, M.J., Hermosín-Gutiérrez, I. \& Pérez-Coello, M.S., 2011a. Micro-oxygenation and oak chip treatments of red wines: Effects on colour-related phenolics, volatile composition and sensory characteristics. Part I: Petit Verdot wines. Food Chem. 124, 727-737.

Cejudo-Bastante, M.J., Hermosín-Gutiérrez, I. \& Pérez-Coello, M.S., 2011b. Micro-oxygenation and oak chip treatments of red wines: Effects on colour-related phenolics, volatile composition and sensory characteristics. Part II: Merlot wines. Food Chem. 124, 738-748.

Commission Regulation (EC), 2006. 1507/2006 of 11 October. Official Journal of the European Union, October 12, 2006, L280/9-L280/11.

Del Álamo-Sanza, M. \& Nevares-Domínguez, I., 2006. Wine aging in bottle from artificial systems (staves and chips) and oak woods: Anthocyanin composition. Anal. Chim. Acta 563, 255-263. 
Del Álamo-Sanza, M., Fernández-Escudero, J.A. \& Castro-Torío, R., 2004. Changes in phenolic compounds and colour parameters of red wine aged in oak chips and in oak barrels. Food Sci. Technol. Int., 10, 233-241.

Fernández-Pachón, M.S., Villaño, D., García-Parrilla, M.C. \& Troncoso, A.M., 2004. Antioxidant activity of wines and relation with their polyphenolic composition. Anal. Chim. Acta 513, 113-118.

García-Carpintero, E.G., Gómez Gallego, M.A., Sánchez-Palomo, E. \& Gónzález Viñas, M.A., 2012. Impact of alternative technique to ageing using oak chips in alcoholic or in malolactic fermentation on volatile and sensory composition of red wines. Food Chem. 134, 851-863.

Gómez-Alonso, S., García-Romero, E. \& Hermosín-Gutiérrez, I., 2007. HPLC analysis of diverse grape and wine phenolics using direct injection and multidetection by DAD and fluorescence. J. Food. Compos. Anal. 20, 618-626.

Gómez-Cordovés, M.C., Suberviola, J. \& Bartolomé, B., 2006. Variaciones producidas en los pigmentos, color y capacidad antioxidante de un vino tinto por el envejecimiento tradicional y por uno de los alternativos: virutas (“chips"). Proc, XXIX Congreso Mundial de la Viña y el Vino. June 2006, Logroño (Spain). p. 66.

Gómez Gallego, M.A., Gómez García-Carpintero, E., Sánchez-Palomo, E., González Viñas, M.A. \& Hermosín-Gutiérrez, I., 2012a. Oenological potential, phenolic composition, chromatic characteristics and antioxidant activity of red single-cultivar wines from Castilla-La Mancha. Food Res. Int. $48,7-15$

Gómez Gallego, M.A., Gómez García-Carpintero, E., Sánchez-Palomo, E., Hermosín-Gutiérrez, I. \& González Viñas, M.A., 2012b. Study of phenolic composition and sensory properties of red grape varieties in danger of extinction from the Spanish region of Castilla-La Mancha. Eur. Food Res. Technol. 234, 295-303.

González-Sáiz, J.M., Esteban-Díez, I., Rodríguez-Tecedor, S. \& Pérez-Del Notario, N., 2014. Modulation of the phenolic composition and colour of red wines subjected to accelerated ageing by controlling process variables. Food Chem. 165, 271-281.

Gortzi, O., Metaxa, X., Mantanis, G. \& Lalas, S., 2013. Effect of artificial ageing using different wood chips on the antioxidant activity, resveratrol and catechin concentration, sensory properties and colour of two Greek red wines. Food Chem. 141, 2887-2895.

Gu, X., Creasy, L., Kester, A. \& Zeece, M., 1999. Capillary electrophoretic determination of resveratrol in wines. J. Agric. Food Chem. 47, 3223-3227.

Guchu, E., Díaz-Maroto, M., Pérez-Coello, M., González-Viñas, M. \& Cabezudo-Ibañez, M., 2006. Volatile composition and sensory characteristics of Chardonnay wines treated with American and Hungarian oak chips. Food Chem. 99, 350-359.

Hermosín Gutiérrez, I., 2003. Influence of ethanol content on the extent of copigmentation in a Cencibel young red wine. J. Agric. Food Chem. 51, 4079-4083.

Hermosín-Gutiérrez, I. \& García-Romero, E., 2004. Anthocyanins of red wine grape cultivars grown in the Spanish region of La Mancha: Characteristic cultivar patterns of grapes and single cultivar wines, and evolution during the ripening of the berry. Alimentaria 41, 127-139.

Hermosín-Gutiérrez, I., Castillo-Muñoz, N., Gómez-Alonso, S. \& GarcíaRomero, E., 2011. Flavonol profiles for grape and wine authentication. In: Ebeler, S.E., Takeoka, G.R. \& Winterhalter, P. (eds). Progress in authentication of food and wine. ACS Symposium Series. American Chemical Society, Washington, DC. pp. $113-129$.

Kallithraka, S., Tsoutsouras, E., Tzourou, E. \& Lanaridis, P., 2006. Principal phenolic compounds in Greek red wines. Food Chem. 99, 784-793.

Lamuela-Raventós, R.M., Romero-Pérez, A.I., Waterhouse, A.L. \& De la Torre-Boronat, M.C., 1995. Direct HPLC analysis of cis- and transresveratrol and piceid isomers in Spanish red Vitis vinifera wines. J. Agric. Food Chem. 43, 281-283.
Landrault, N., Poucheret, P., Ravel, P., Gasc, F., Cros, G. \& Teissedre, P.L., 2001. Antioxidant capacities and phenolics levels of French wines from different varieties and vintages. J. Agric. Food Chem. 49, 3341-3348.

Mattivi, F., Reniero, F. \& Korhammer, S., 1995. Isolation, characterization, and evolution in red vinification of resveratrol monomers. J. Agric. Food Chem. 43, 1820-1823.

Mazza, G., Fukumoto, L., Delaquis, P., Girard, B. \& Ewert, B., 1999 Anthocyanins, phenolics, and color of Cabernet franc, Merlot, and Pinot noir wines from British Columbia. J. Agric. Food Chem. 47, 4009-4017.

McCord, J., 2003. Application of toasted oak and micro-oxygenation to aging of Cabernet sauvignon wines. Aust. NZ Grape Wine, 474, 43-53.

Monagas, M. \& Bartolomé, B. 2009. Anthocyanins and anthocyaninderived compounds. In: Moreno-Arribas, M.V. \& Polo, M.C. (eds). Wine chemistry and biochemistry. Springer Science and Business Media, New York. pp. $529-570$

Moyano, L., Chaves, M., Ruiz, M.J., Zea, L \& Medina, M., 2009. Change in colour of oloroso wine subjected to accelerated aging with oak chips. Proc. 2nd World Congress of Vine and Wine, 7th General Assembly of the OIV, June 2009 Zagreb (Croatia).

Nixdorf, S.L. \& Hermosín-Gutiérrez, I., 2010. Brazilian red wines made from the hybrid grape cultivar Isabel: Phenolic composition and antioxidant activity. Anal. Chim. Acta. 659, 208-215.

O.I.V. International Oenological Codex. 2006. Recueil des methodes internationales d'analyse des vins et desmoûts, edition. Office International de la Vigne et du Vin, Paris.

Pérez-Caballero, V., Ayala, F., Echávarri, J.F. \& Negueruela, A.I. 2003. Proposal for a new standard OIV method for determination of chromatic characteristics of wine. Am. J. Enol. Vitic. 54, 59-62.

Pérez-Coello, M.S., Sánchez, M.A., García, E., González-Viñas, M.A., Sanz, J. \& Cabezudo, M.D., 2000. Fermentation of white wines in the presence of wood chips of American and French oak. J. Agric. Food Chem. $48,885-889$

Pérez-Magariño, S., Ortega-Heras, M., Rodríguez-Bencomo, J.J., González-Huerta, C. \& González-Sanjosé, M.L., 2007. Aceptación de los consumidores españoles de las nuevas prácticas enológicas. Proceedings of the XXX Congreso Mundial de la Viña y el Vino. Section Three: Economic and Law, June Budapest, Hungary.

Price, S.F., Breen, P.J., Valladao, M. \& Watson, B.T., 1995. Cluster sun exposure and quercetin in Pinot Noir grapes and wine. Am. J. Enol. Vitic. $46,187-194$

Rentzsch, M., Schwarz, M., Winterhalter, P, Blanco-Vega, D. \& HermosínGutiérrez, I., 2010. Survey on the content of vitisin A and hydroxyphenylpyranoanthocyanins in Tempranillo wines. Food Chem. 119, 1426-1434.

Rentzsch, M., Schwarz, M., Winterhalter, P, Blanco-Vega, D. \& HermosínGutiérrez, I. (2010) Survey on the content of vitisin A and hydroxyphenylpyranoanthocyanins in Tempranillo wines. Food Chem. 473, 119, 14261434

Ribéreau-Gayon, P., Glories, Y., Maujean, A. \& Dubourdieu, D., 2000 (2nd ed). Phenolic compounds. In: Handbook of Enology. Volume 2. The Chemistry of Wine. Stabilization and Treatments. In Ribéreau-Gayon, Y. Glories, A. Maujean, \& D. Dubourdieu (Eds.). John Wiley \& Sons Ltd: Chichester. pp $141-203$.

Sánchez-Moreno, C., Cao, G., Ou, B. \& Prior, R. 2003. Anthocyanin and proanthocyanidin content in selected white and red wines. Oxygen radical absorbance capacity comparison with nontraditional wines obtained from high bush blueberry. J. Agric. Food Chem. 51, 4889-4896.

Sartini, E., Arfelli, G., Fabiani, A. \& Piva, A., 2007. Influence of chips, lees and microoxygenation during aging on the phenolic composition of a red Sangiovese wine. Food Chem. 104, 1599-1604 
Schwarz, M., Picazo-Bacete, J.J., Winterhalter, P. \& Hermosín-Gutiérrez, I., 2005. Effect of copigments and grape cultivar on the color of red wines fermented after the addition of copigments. J. Agric. Food Chem 53, 83728381

Soto Vázquez, E., Río Segade, S. \& Orriols Fernández, I., 2010. Effect of the winemaking technique on phenolic composition and chromatic characteristics in young red wines. Eur. Food Res. Tech. 231, 789-802.
Sun, B., Ribes, A.M., Leandro, M.C., Belchior, A.P. \& Spranger, M.I., 2006. Stilbenes: Quantitative extraction from grape skins, contribution of grape solids to wine and variation during wine maturation. Anal. Chim. Acta. 563, 382-390. 